Military Technical College

Kobry El-Kobba

Cairo, Egypt

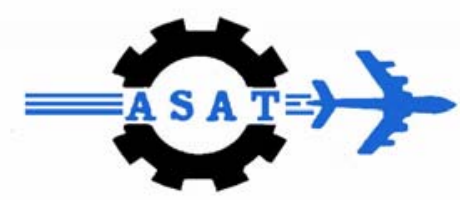

12-th International Conference

on

Aerospace Sciences \&

Aviation Technology

\title{
EXPERIMENTAL VERIFICATION OF TWO STAGE ALGORITHM FOR HEALTH MONITORING OF AEROSPACE STRUCTURES
}

\author{
Amin, M. S. * and Abdelkhalik, M. **
}

\begin{abstract}
A system of continuous structural health monitoring would be desirable for early warning of distress in major engineering systems such as space structures and orbiting spacecrafts since they are susceptible to the impact of meteoroids and orbital debris. However, the complexity of some large space structures makes the use of the traditional non-destructive evaluation (NDE), such as visual inspection and instrumental evaluation methods, impractical. A recent development in structural health monitoring systems (SHM) is the use of vibration-based damage identification (VBDI) methods. These methods use limited instrumentation to detect the changes in the measured modal characteristics of the structure, that is, its frequencies and mode shapes. These characteristics change with the physical properties of the structure (stiffness, mass and damping matrices) and can be used to help find the location and extent of damage. Optimal matrix update method is one of the VBDI algorithms that depend on finite element modeling (FEM) of the structure. The FRF differences method is also one of the VBDI techniques that depends on the directly measured frequency response functions data and is therefore referred to as non model-based damage identification algorithm. A proposed two stage algorithm combining the aforementioned model-based and non-model based methods introduced to improve the reliability of damage detection. The algorithm presented a simple robust sequential scheme of VBDI techniques and has proven an acceptable level of success when tested through numerical simulation in the presence of simulated random errors. The present paper focuses on the experimental verifications through the implementation of the algorithm to evaluate its efficiency in identifying damage in real large-scale space structures. The experimental verifications are highlighted through modal tests designed to provide estimates of damage in a 3D eight-bay freefree frame representing part of the International Space Station ISS. Details of tests on a healthy structure as well as on a damaged structure in which predetermined damage has been introduced are presented. This combination allowed identifying different levels of damage for real monitoring of structures using minimum modal data base even when the structure is somewhat complex.
\end{abstract}

\section{Keywords}

Damage detection, structural health monitoring, frequency response function, Optimization, optimal matrix update.

\footnotetext{
* Ph.D, Civil Eng. Department, Military Technical College, Egyptian Armed Forces, Egypt.

** Msc, Civil Eng. Department, Military Technical College, Egyptian Armed Forces, Egypt.
} 


\title{
Nomenclature
}

\author{
K System stiffness matrix. \\ M System mass matrix. \\ FRF Frequency response functions. \\ DDI Damage detection index. \\ $\delta$ K Perturbations to the system stiffness matrix. \\ $\varphi_{i} \quad$ The $i^{\text {th }}$ mass-orthonormal mode shape \\ $\lambda_{i} \quad$ The $i^{\text {th }}$ eigenvalue (squared frequency). \\ $\delta \varphi_{i} \quad$ The change in the $i^{\text {th }}$ mode shape. \\ $\delta \lambda_{i}$ The change in the $i^{\text {th }}$ eigenvalue. \\ || || The Frobenius norm.
}

\section{Introduction}

The structural health monitoring of major engineering structures such as space structures, orbiting spacecrafts, and civil infrastructures have become an urgent necessity to prevent potential catastrophic failures. Traditional NDE techniques, such as visual inspection and instrumental evaluation, have often been employed as the preferred means of inspection of structures. These methods require that all portions of the structure are accessible. This may be impractical, particularly when the structure is complex and/or large in size and orbiting in the space, such as the main supporting structure of the international space station ISS.

Recent development in the structural health monitoring has led to the evolution of various SHM systems that use VBDI techniques. Vibration characteristics of a structure, that is, its frequencies, mode shapes, and damping are directly affected by the physical characteristics of the structure including its mass and stiffness. Damage reduces the stiffness of the structure and alters its vibration characteristics. Therefore, measured changes in the vibration characteristics can be used as indicators of the overall integrity of the structure and means of finding the location and extent of damage. Among the advantages offered by VBDI is that the location of damage need not be known in advance, many other advantages can be found in [1].

However, in practice there are a number of limitations associated with VBDI techniques. Among these limitations are the following:

- Vibration characteristics are global properties of the structure, and although they are affected by local damage, they may not be very sensitive to such damage. In particular the changes in the lower frequencies and mode shapes caused by local damage are often insignificant. The effect of damage on higher modes may be more substantial, but such modes are difficult to measure with accuracy.

- It is impractical to measure the mode shape components along all of the independent degree of freedom DOF's of a large structure. The measured mode shapes are thus incomplete. The identification damage using measurements at a limited number of sensors is a problem that has a non-unique solution solved by means of sophisticated and complex mathematical techniques including nonlinear optimization. 
An excellent and extensive review of the VBDI algorithms that have been carried out on the development of mathematical algorithms can be found in [1, 2 \& 3].

The optimal matrix update method is one of the VBDI algorithms that depend on finite element modeling (FEM) of the structure and is therefore referred to as model-based damage identification method [1, 2 \& 3]. In this method a constrained non linear optimization problem is solved for updating the physical property matrices, usually the stiffness matrix, so that the frequencies and mode shapes of the modified system closely match the measured characteristics of the damaged structure. The level of success of this method in identifying damage is influenced by the FEM errors, modal parameters extraction and measuring errors. To some extent this limitation can be overcome when a matrix update method is combined with another procedure, which could narrow down the region of potential damage. Among the identification algorithms that independent on the FEM and modal extraction errors, is the FRF differences method [ $4 \& 5$ ]. This method depends on the directly measured frequency response functions data and is therefore referred to as non model-based or modalbased damage identification algorithm. In a previous study [6], a new damage identification algorithm is introduced to improve the reliability of damage detection. In which, the optimal matrix update method (model-based method) is combined with the FRF difference method (non-model based method). The algorithm has proven an acceptable level of success when tested through numerical simulation to predicting damage on the basis of analytically created modal test data [6].

This paper focuses on assessing the effectiveness of the combined algorithm in identifying damage in real large-scale space structures. It is implemented to predetermined damage induced in an eight-bay 3D free-free frame representing part of the International Space Station ISS on the basis of experimentally measured modal testing. Brief of Modal tests on a healthy structure as well as on a damaged structure in which predetermined damage is introduced here in. More details on the experimental tests can be found in [7]. The experimental verification procedure includes an optimal pre-test planning for modal testing. The space frame is first tested to obtain the baseline vibration characteristics of the healthy structure. Then a combination of mathematical procedures is used to acquire and select FRF's modal data for the lower non-rigid body modes. The baseline FEM of the structure is constructed and refined so that the analytical properties derived from the model match the measured properties. A physically motivated strategy for constructing and correlating the FEM of the space frame is described in [8]. Details of modal tests on the frame structure in which many scenarios for predetermined damage have been introduced are presented next. The acquired FRF's for the damaged structure is paired with their counterparts of the healthy structure to calculate the DDI for the affected degrees of freedom [6]. The Damaged region is identified based on the maximum values of the DDI's from which only limited number of elements are determined as susceptible candidates for damage. Finally, a suitable non-linear optimisation problem is formulated, whose design variables are the candidate elements determined in the previous step and its solution is the identification of damage location and severity. Different damage scenarios are then predicted on the basis of modal test data and the predictions are compared with the known damage. 


\section{THEORETICAL BACKGROUND FOR THE COMBINED ALGORITHM}

\section{Optimal Matrix Update Method}

The theoretical basis for the optimal matrix update methods has been extensively covered in the literature [1, 2 \&3]. A brief description is presented here for the sake of completeness. Vibration-based damage detection algorithms use the basic eigenvalue equation, which for the healthy structure is given by

$$
K \varphi_{\mathbf{i}}=\lambda_{\mathbf{i}} \mathbf{M} \varphi_{\mathbf{i}}
$$

Damage in the structure is assumed not to cause any changes in the system mass matrix, but alters the stiffness matrix. A change in the stiffness would also change the frequencies and the mode shapes. The eigenvalue equation for the damaged structure is thus given by

$$
\left[\mathbf{K}+\delta \mathbf{K}-\left(\lambda_{\mathbf{i}}+\delta \lambda_{\mathrm{i}}\right) \mathbf{M}\right]\left[\varphi_{\mathrm{i}}+\delta \varphi_{\mathrm{i}}\right]=\mathbf{0}
$$

On multiplying Equation (2) by $\varphi \mathrm{i}^{\top}$, using Equation (1) and its transpose and neglecting the higher order infinitesimal terms, rearranging terms and given that $\varphi_{d i}$ is the $\mathrm{I}^{\text {th }}$ mode shape of the damaged structure we get

$$
\varphi_{\mathrm{i}}^{\top} \delta \mathrm{K} \varphi_{\mathrm{di}}=\delta \Lambda_{\mathrm{i}} \varphi_{\mathrm{i}}^{\top} \mathrm{M} \varphi_{\mathrm{di}}
$$

The changes in stiffness matrix $\delta \mathrm{K}$ can be expressed as the weighted sum of the stiffness matrices of the damaged elements. The weighting factors, which are the unknown in the problem, define the severity of damage in the affected elements. If the reduction in the stiffness of element $\mathbf{k}_{\mathbf{j}}$ is expressed as $\beta_{\mathbf{j}} \mathbf{k}_{\mathbf{j}}$, we have

$$
\delta K=-\sum_{j} \beta_{j} k_{j}
$$

Substitution of Equation (4) in Equation (3) gives

$$
\sum_{\mathrm{j}=1}^{\mathrm{n}} \varphi_{\mathrm{i}}^{\top} \mathbf{k}_{\mathrm{j}} \varphi_{\mathrm{di}} \beta_{\mathrm{j}}=-\delta \lambda_{\mathrm{i}} \varphi_{\mathrm{i}}^{\top} \mathbf{M} \varphi_{\mathrm{di}}
$$

or

$$
\mathbf{D} \boldsymbol{\beta}=-\delta \boldsymbol{\lambda}
$$

Where $\mathrm{n}$ is the number of elements, $\mathbf{D}$ is an $\mathrm{m}$ by $\mathrm{n}$ matrix whose elements are $\mathrm{d}_{\mathrm{ij}}=\varphi_{\mathrm{i}}^{\top} \mathbf{k}_{\mathrm{j}} \varphi_{\mathrm{di}} / \varphi_{\mathrm{i}}^{\top} \mathrm{M} \varphi_{\mathrm{di}}, \beta$ is the n-vector of the unknown changes in elemental stiffness matrices, $\delta \lambda$ is the m-vector of measured eigenvalue changes, and $\mathrm{m}$ is the number of measured modes. In general $m$ will be less than $n$ so that the problem defined by Equation (6) is underdetermined and has an infinite number of solutions. In order to obtain a unique solution an optimization problem needs to be solved, in which a selected objective function is minimized subjected to a specified set of 
constraints. In matrix update algorithms the quadratic norm of the stiffness changes given by $\mathrm{J}=\boldsymbol{\beta}^{\top} \boldsymbol{\beta}$ is minimized. Equation (6) defines one set of constraints on the problem. For the damaged structure the following additional constraints must be placed on the stiffness changes

$$
0 \leq \boldsymbol{\beta} \leq 1
$$

The above nonlinear optimization problem is solved using the optimization routine based on a sequential quadratic programming method available in MATLAB.

The number of measured modes, $\mathrm{m}$, would usually be much smaller than the number of elements, $\mathrm{n}$. In addition in a modal test it is often impractical to measure the response at all of the DOF included in a finite element model. One way to compare the analytical and experimental data is to reduce the DOFs in the analytical model or to expand the measured mode shapes to match the FEM DOFs. Reduction of DOFs in the analytical model can be carried out by using one of the standard methods, such as Guyan reduction, dynamic condensation, and system equivalent reduction expansion process (SEREP) [9]. The SEREP technique was used in the present work.

\section{Frequency Response Function Differences}

Modal-based identification methods are categorized into two main categories: Modaldata based methods such as frequency shifts and mode shape curvature, and FRFdata based methods such as the FRF difference method [1]. The FRF-data are favorable over the modal-based methods since it is not contaminated by modal extraction errors since the FRF-data are directly measured test data and can provide much more damage information in a desired frequency range [10 \&11]. In the present study a Damage Detection Index DDI that interprets the differences between the FRF's measured for the healthy and damaged structure can be used to detect damaged region. This index introduced by Napolitano et al [4] and modified by [6]. The modification insures that all the FRF' data is included consequently the modified DDI is reduced to the form:

$$
\mathbf{D D I}=\left(\frac{\sum_{\mathbf{i}=1}^{\mathrm{n}}\left|\mathbf{F I}_{\mathbf{i}}-\mathbf{F D}_{\mathbf{i}}\right|}{\sum_{\mathbf{i}=1}^{\mathrm{n}} \mathbf{F I}_{\mathbf{i}}}\right) \times 100
$$

Where $\mathrm{Fl}_{\mathrm{i}}$ and $\mathrm{FD}_{\mathrm{i}}$ are the amplitude of the FRF's of the healthy and damaged structure respectively, $\mathrm{n}$ is the number of the points in the sweep rang, in which the FRF's are sampled in. In the present study the DDI is calculated to include the frequency band of interest. This non-model-based technique is characterized by its simplicity and speed in data acquisition and elaboration since it is free from modal analysis, and is able to perform a real-time monitoring of in-service structures. 


\section{Description of the Test Specimen}

The test specimen used in this study is an erectable aluminium space frame made from commercially available hardware (Meroform M12), Fig.1. The design of the joint node allows the frame to be assembled into numerous configurations in any of three orthogonal directions, thereby providing structures with varying complexity. Fig. 2 shows details of the nodes and struts. The struts have threaded solid steel end connectors, which when tightened into the node also clamp the tube by means of an internal compression fitting. This feature allows any of the frame struts to be replaced by another one of a different (smaller) size without disassembly of the entire unit, which is very useful in simulating damage in any of the frame struts.

A finite element model of the space frame is shown in Fig. 3. The frame consists of eight bays, each of which is a cube with 707 long $\mathrm{mm}$ sides. Since the modal tests are to be conducted in a free-free condition, no supports are identified in the model. The nominal physical properties of the frame components are listed in Table 1. All tubes in the vertical $(x-y)$ planes are $30 \mathrm{~mm}$ in diameter and have a wall thickness of $1.5 \mathrm{~mm}$. Tubes in the horizontal $(x-z)$ planes, other than those already included in the vertical planes, are $22 \mathrm{~mm}$ by $1.5 \mathrm{~mm}$. Lumped masses simulating payloads, each of $1.75 \mathrm{~kg}$, are added to nodes $4,9,25,28$, and 36 . Masses of $2.75 \mathrm{~kg}$ are added at nodes 6,17 , and 30 . These design features give well-separated modes and are adopted so as to facilitate the evaluation of damage detection methods.

\section{Design of Modal Test Setup}

Prior to modal testing a number of issues related to the test set-up were carefully considered. One of the main requirements in a modal test set-up for damage detection is an optimum selection of the response and excitation points. Sensors and actuators can be placed at only a limited number of degrees of freedom when dealing with a complex and large structure. The most common sensor placement methods use various scales to measure the significance of candidate sensor locations with respect to the observability of the target modes. In damage identification the excitation points should be selected in a way that insures the optimal excitation of all target modes. The first few lower modes are usually used in damage identification, since they are generally the only modes that can be measured reliably and with acceptable accuracy. Generally, the criteria for selecting the driving points are: (1) the excitation must produce a reasonable displacement for most of the modes of interest, (2) driving points must be far away from each other to allow for a meaningful reciprocity check. In this work selection of the excitation or driving points was based on the FEM predictions and through preliminary modal tests carried out to investigate different issues. An examination of the FRFs of many response points showed that, placing the exciters at DOFs (2-Y) and (33-Z) would best fulfill the requirements outlined above. Considering that rotations are difficult to measure, response measurements were limited to the three translational DOFs at each of the 36 ball nodes. In general response was measured all 108 DOFs so that the measured mode shapes were as complete as practicable. However, in carrying out the subsequent validation studies the effect of using only a subset of the 108 DOFs was also investigated, with a view to determine whether damage could be identified on the basis of measurements along a very limited number of selected DOFs. 


\section{Finite Element Model Construction and Updating}

The construction of a FE model usually involves some simplifying assumptions. These assumptions ignore detailed features, which would require a fine mesh for accurate geometric representation of the structural elements and boundary conditions. In developing a FE model of the eight-bay space frame used for the experimental validation in this work careful consideration was given to the modeling of the joint. The procedure for modeling the member-end joint such as that shown in Fig. 2 is to assume that the joint behaves as flexible joints. The dynamic characteristics of the approximate model may deviate significantly from the experimental values obtained from modal tests on the healthy structure and could lead to subsequent difficulties in identifying damage. In such a case model updating is carried out using physically motivated strategy for constructing and correlating the FEM of the space frame [8]. Although the frequencies and mode shapes of the updated model may closely match the experimental values, the model may not fully represent the true physical characteristics of the test specimen.

Using the physical parameters obtained from the static tests [8], finite element model was constructed for the individual tubular members. Since It was recognized that the connection of the aluminum tube to the ball node through a bolt and pressure fitting would result in significant flexibility in the joint. A refined model was therefore constructed in which each strut was represented by five 3-D beam elements as shown in Fig.4, giving a total of 36 DOFs per strut. The physical properties of each of the five elements of the struts were derived from measurements and static tests referred to earlier are listed in Table 2. The five-element strut model was used to construct the FEM of the space frame, which includes 109 struts and 36 nodes as shown in Fig. 3. The space frame model had a total of 2928 DOFs using a consistent mass formulation in calculating the modal parameters.

\section{Modal Testing of the Undamaged Frame}

As soon as the space frame was assembled, a series of modal tests was performed. The primary objective of this set of modal tests was to correlate the FE model of the undamaged space frame. Fig. 5 shows the FRF at one of the driving points DOF (2Y) due to excitation at DOF (33-Z). An examination of the peaks of the FRF plot shows that the lowest three modes are well separated. Table 3 shows the experimental and analytical frequencies for the first few modes as well as the results of mass orthogonality check between the two sets of modes, with a coarse FE model good correlation exists for the first three modes. The refined model gives very good correlation for seven out of the first nine modes.

\section{Modal Testing of the Damaged Frame}

Modal tests were carried out on several frame configurations in which predetermined damage had been introduced. Simulated damage was introduced either by replacing a $30 \mathrm{~mm}$ diameter tube with a $22 \mathrm{~mm}$ or by making a saw cut in one or more tubes representing nominal stiffness reduction of $(100 \%)$. Replacement of a tube by that of a smaller diameter resulted in a comparatively smaller change in the stiffness 
representing nominal value of $(50 \%)$, and hence in only small reductions in the measured frequencies. Introduction of saw cuts led to substantial reduction in one or more measured frequencies.

In the present paper results are presented for only five of those cases in which damage was introduced at single and multiple sites representing different severities. Table 4 shows the damage cases configurations. As discussed earlier, damage was assumed to affect only the stiffness of the structure leaving the structural mass unchanged. Table 5 shows the change in frequencies of the lowest three modes produced in each of the five damage cases. Fig. 6 and Fig. 7 show two samples of the FRFs plots obtained during the tests of the damaged frame compared to the healthy FRFs at one of the driving points DOF (2-Y) due to excitation at DOF (33-Z).

\section{Results and Conclusions}

Results of experimental damaged cases: DE1, DE2 and DE3 are summarized in Fig.8 to Fig.10. It can be seen in figures labeled (a), that when all the 109 elements were included in the optimization problem, the damage identification algorithm which is based on the optimal matrix update only, was always able to identify the damage location and severity with acceptable accuracy for all the severe damage cases. However in all the identification results, false elements were identified as damaged ones and the severity of damage was not accurately determined. The modified FRF differences technique was always able to identify correctly the affected nodes when a severe damage is introduced in the structure at single or multiple sites as it can be seen in figures labeled (b). The isolation of the damaged region, hence reducing the design variables, always led to an improvement in the performance of the modified algorithm. It improved the identification of the damage severity and reduced the number of false predictions as it can be seen in figures labeled (c).

The results of experimental damage cases DE4 and DE5 are summarized in Fig.11 and Fig.12. In case of including all the 109 elements in the optimization process, figures labeled (a), the damage identification algorithm was unable to identify the lightly damaged elements in the mixed damage scenarios, which is demonstrated by damage scenarios DE4 E5. and D The FRF differences technique was sometimes not able to precisely determine that the nodes which are connected to lightly damaged elements are affected nodes in case of the presence of severely damaged elements, as in damage scenario DE5. The correct identification of the damaged region usually improved the performance of the identification algorithm.

The case study in the present paper included the most probable issues that may be encountered in real life for implementing the VBDI for structural health monitoring. Such as the complexity of the test article, the corrupted measured data acquired used in the different procedures of the algorithm and the large size FEM (2928 DOF). Regardless the aforementioned problem, the two step algorithm was able to identify the damage with relatively acceptable success using limited measured degrees of freedom (79 DOF). Also, the isolation of the damaged region using FRF differences positively influenced the performance of the optimal matrix update method. 


\section{REFERENCES}

1. Doebling, S. W., Farrar, C. R., Prim, M. B., and Shevitz, D. W., "Damage Identification and Health Monitoring of Structural and Mechanical Systems From Changes in Their Vibration Characteristics: A Literature Review," Los Alamos National Laboratory Report LA-13070-MS., 1996.

2. Hossiotis, S. and Jeong, G.D., Identification of Stiffness Reductions Using Natural Frequencies, ASCE, Journal of Engineering Mechanics, Vol. 121, No. 10, October 1995.

3. Li, W. L., A New Method for FEM Structural Dynamic Model Updating and Joint Identification, 18th International Modal Analysis Conference, IMAC, San Antonio, Texas, Feb. 3-6, 2000, pp. 454-460.

4. Napolitano, L., Fedele, P., Viscardi, M. and Lecce, L., "Damage Identification and Location on Typical Aeronautical Structure", SPIE Vol. 3397, 1998.

5. Wang, Z., Lin, R.M. and Lim, M.K. "Structural Damage Detection Using Measured FRF Data", Computer Methods in Applied Mechanics and Engineering, vol. 147, 1997.

6. Amin, M. S., Abdelkhalik, M., and Zidan, M. K., " Structural Health Monitoring Using Two Stage Algorithm Combines Non Model-Based and Model Based Techniques", Proceedings of the $6^{\text {th }}$ ICCAE Conf. $16-18$ May, 2006, Military Technical Collage, Cairo, Egypt, SAD8 pp 102-122.

7. Amin, M. S., "An Integrated Vibration-Based Structural Health Monitoring System", Ph.D. thesis, Carleton University, Ottawa, Canada, 2002.

8. Amin, M. S., and Humar, j. L. " FEM Updating for Structural Health Monitoring of Aerospace Structures", Proceedings of the 5th ICCAE Conf. 23 -25 Nov., 2004, Military Technical Collage, Cairo, Egypt, SAD5, pp 49-60.

9. O'Callahan, J., Avitabile, P., Riemer, R. System equivalent reduction expansion process, 7th International Modal Analysis Conference, Las Vegas, Nevada, Feb. 1989.

10. Banks, H.T., Inman, D.J. and Wang, Y., "An Experimentally Validated Damage Detection Theory in Smart Structures", Journal of Sound and Vibration, vol. 191(5), 1996.

11. Wang, Z., Lin, R.M. and Lim, M.K. "Structural Damage Detection Using Measured FRF Data", Computer Methods in Applied Mechanics and Engineering, vol. 147, 1997. 
Table 1: Properties of the Frame Components

\begin{tabular}{|c|c|c|c|c|}
\hline Component & $\begin{array}{c}\text { Dimensions } \\
(\mathbf{m m})\end{array}$ & $\begin{array}{c}\text { Cross- } \\
\mathbf{s e c t i o n a l} \\
\mathbf{a r e a}\left(\mathbf{m m}^{\mathbf{2}}\right)\end{array}$ & $\begin{array}{c}\text { Inertia } \\
\left(\mathbf{m m}^{\mathbf{4}} \mathbf{)}\right.\end{array}$ & $\begin{array}{c}\text { Weight } \\
\mathbf{( g m})\end{array}$ \\
\hline Aluminium node & 46 diameter & - & - & 80 \\
\hline Tubes in $(x-y)$ planes & $707 \times 30 \times 1.5$ & 134.3 & 13673.7 & 350 \\
\hline Tubes in $(x-z)$ planes & $707 \times 22 \times 1.0$ & 65.97 & 3645.0 & 230 \\
\hline Diagonal tubes in $(x-y)$ planes & $1000 \times 30 \times 1.5$ & 134.3 & 13673.7 & 450 \\
\hline Diagonal tubes in $(x-z)$ planes & $1000 \times 30 \times 1.0$ & 65.97 & 3645.0 & 275 \\
\hline
\end{tabular}

Table 2: Physical properties of the finite elements used to model the tubes

\begin{tabular}{|c|c|c|c|c|}
\hline Element no. & $\begin{array}{c}\text { Modulus of } \\
\text { Elasticity }(\mathbf{P a})\end{array}$ & Density $\mathbf{( \mathbf { k g } / \mathbf { m } ^ { \mathbf { 3 } } )}$ & $\begin{array}{c}\text { Cross sectional } \\
\text { Area }\left(\mathbf{m}^{\mathbf{2}}\right)\end{array}$ & $\begin{array}{c}\text { Inertia } \mathbf{I}_{\mathbf{z}}, \mathbf{I}_{\mathbf{y}} \\
\left(\mathbf{m}^{\mathbf{4}}\right)\end{array}$ \\
\hline $\mathrm{EL}(1)$ & $0.67 \mathrm{E}+11$ & $0.27 \mathrm{E}+04$ & $9.55 \mathrm{E}-04$ & $1.8 \mathrm{E}-07$ \\
\hline EL (2) & $0.2 \mathrm{E}+12$ & $0.78 \mathrm{E}+04$ & $1.179 \mathrm{E}-04$ & $1.105 \mathrm{E}-09$ \\
\hline EL (3) tube $(30 \times 1.5)$ & $0.67 \mathrm{E}+11$ & $0.27 \mathrm{E}+04$ & $1.343 \mathrm{E}-04$ & $1.3674 \mathrm{E}-08$ \\
\hline EL (3) tube $(22 \times 1.0)$ & $0.67 \mathrm{E}+11$ & $0.27 \mathrm{E}+04$ & $6.597 \mathrm{E}-05$ & $3.645 \mathrm{E}-09$ \\
\hline
\end{tabular}

Table 3: Comparison between measured and analytical frequencies of the undamaged frame

\begin{tabular}{|c|c|c|c|c|}
\hline $\begin{array}{c}\text { Mode } \\
\text { No. }\end{array}$ & $\begin{array}{c}\text { Measured } \\
\mathbf{( H z}\end{array}$ & $\begin{array}{c}\text { Analytical } \\
\mathbf{( H z}\end{array}$ & $\boldsymbol{\delta}_{\text {correlation }}$ & Discrepancy \% \\
\hline 1 & 50.98 & 50.98 & 0.989 & 0.00 \\
\hline 2 & 52.15 & 52.31 & 0.997 & 0.30 \\
\hline 3 & 57.51 & 57.49 & 0.996 & 0.03 \\
\hline 4 & 90.13 & 91.67 & 0.940 & 1.70 \\
\hline 5 & 92.41 & 92.26 & 0.955 & 0.16 \\
\hline 6 & 99.17 & 100.5 & 0.936 & 1.34 \\
\hline 7 & 101.63 & 102.4 & 0.967 & 0.75 \\
\hline 8 & 106.17 & 113.6 & 0.916 & 7.00 \\
\hline 9 & 109.91 & 114.9 & 0.844 & 4.54 \\
\hline
\end{tabular}

Table 4: Experimental damage scenarios

\begin{tabular}{|c|c|c|c|}
\hline Damage Case ID & $\begin{array}{c}\text { Damaged } \\
\text { Elements }\end{array}$ & $\begin{array}{c}\text { Elements } \\
\text { Connectivity }\end{array}$ & $\begin{array}{c}\text { Damage } \\
\text { Severity \% }\end{array}$ \\
\hline DE1 & 38 & $20-24$ & 100 \\
\hline \multirow{2}{*}{ DE2 } & 38 & $20-24$ & 100 \\
& 102 & $24-27$ & 100 \\
\hline \multirow{2}{*}{ DE3 } & 98 & $18-21$ & 100 \\
& 99 & $19-24$ & 100 \\
\hline \multirow{3}{*}{ DE4 } & 38 & $20-24$ & 50 \\
& 42 & $24-28$ & 100 \\
& 78 & $20-22$ & 100 \\
\hline \multirow{3}{*}{ DE5 } & 35 & $17-21$ & 50 \\
& 36 & $18-22$ & 50 \\
& 37 & $19-23$ & 50 \\
& 38 & $20-24$ & 100 \\
\hline
\end{tabular}


Table 5: Changes in the frequencies caused by damage

\begin{tabular}{|c|c|c|c|c|c|c|c|c|c|c|c|}
\hline \multirow{2}{*}{$\begin{array}{c}\text { Mode } \\
\text { No. }\end{array}$} & \multirow{2}{*}{$\begin{array}{l}\text { Measured } \\
(\mathrm{Hz})\end{array}$} & \multicolumn{2}{|c|}{ DE1 } & \multicolumn{2}{|c|}{ DE2 } & \multicolumn{2}{|c|}{ DE3 } & \multicolumn{2}{|c|}{ DE4 } & \multicolumn{2}{|c|}{ DE5 } \\
\hline & & $\begin{array}{l}\text { Freq. } \\
(\mathrm{Hz})\end{array}$ & $\% \Delta \omega$ & $\begin{array}{l}\text { Freq. } \\
(\mathrm{Hz})\end{array}$ & $\% \Delta \omega$ & $\begin{array}{l}\text { Freq. } \\
(\mathrm{Hz})\end{array}$ & $\% \Delta \omega$ & $\begin{array}{l}\text { Freq. } \\
(\mathrm{Hz})\end{array}$ & $\% \Delta \omega$ & $\begin{array}{l}\text { Freq. } \\
(\mathrm{Hz})\end{array}$ & $\% \Delta \omega$ \\
\hline 1 & & 50.99 & 0.02 & 41.83 & 7.95 & 42.05 & 17.52 & 28.48 & 44.13 & 49.63 & 2.65 \\
\hline 2 & & 32.83 & 37.0 & 32.69 & 37.32 & 54.40 & 4.31 & 44.43 & 14.8 & 30.01 & 42.45 \\
\hline 3 & 57.51 & 55.96 & 2.70 & 53.72 & 6.60 & 57.38 & 0.22 & 54.56 & 5.13 & 52.02 & 9.55 \\
\hline
\end{tabular}

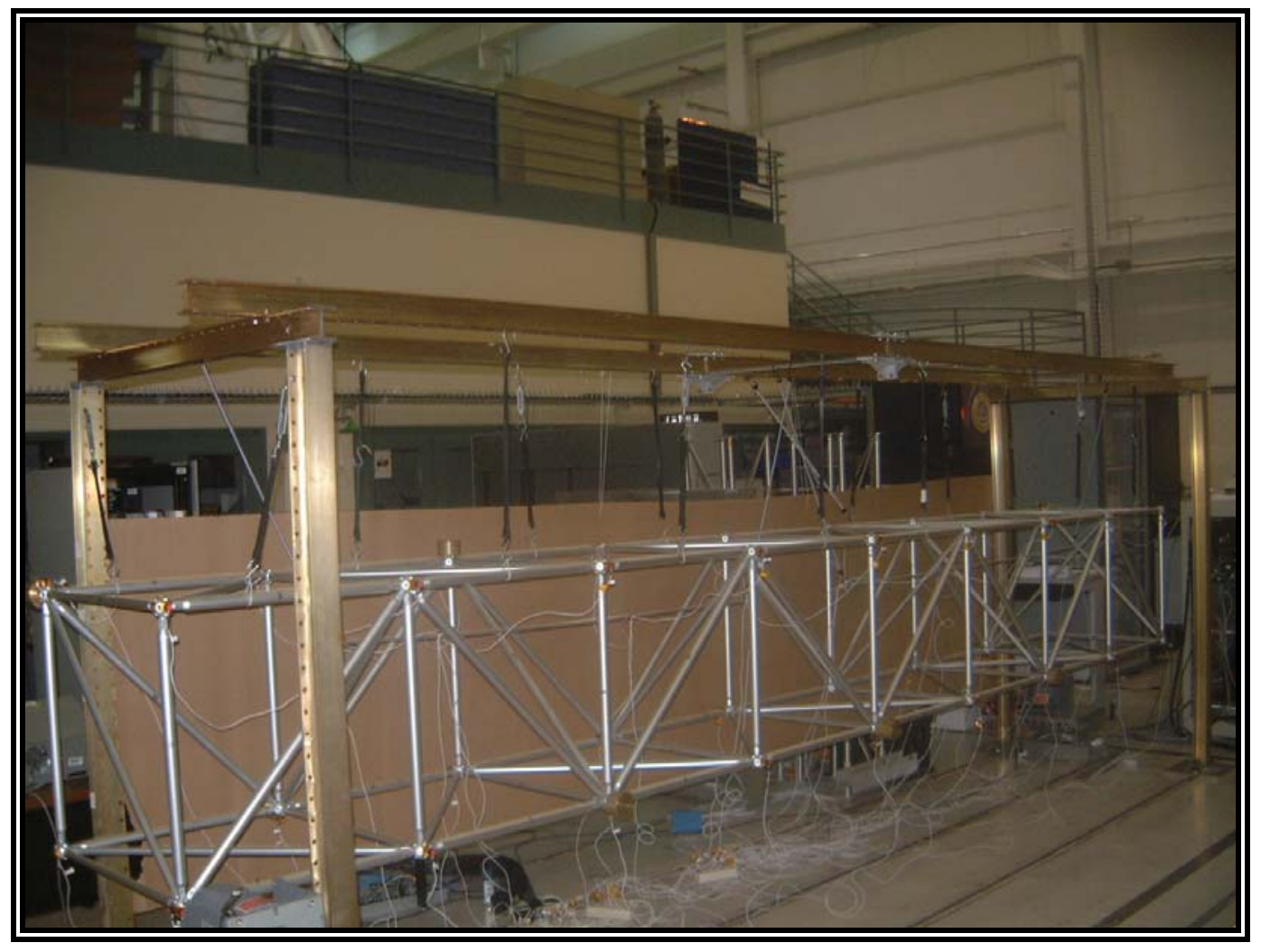

Fig. 1 Complete geometric configuration of the eight-bay space frame, Amin M. (2002).

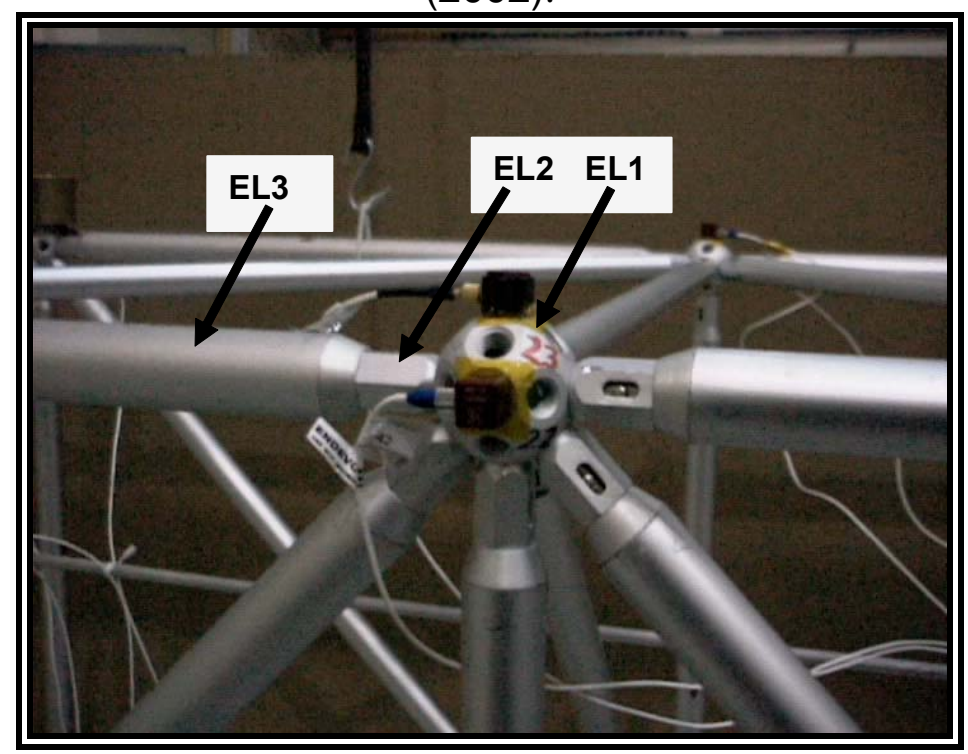

Fig. 2 Finite element model of the aluminum tube and joint subassembly 


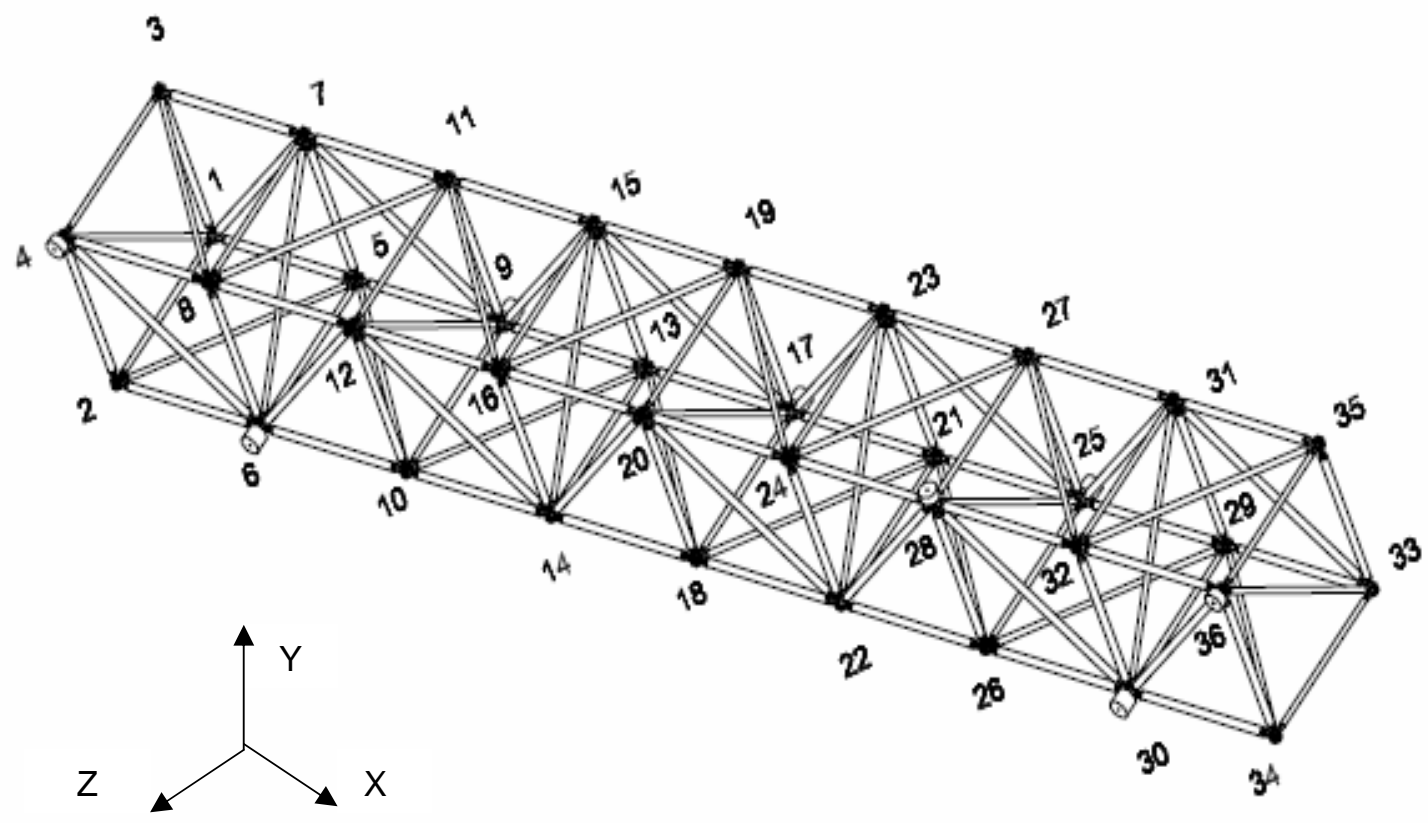

Fig.3 Finite Element Model of Eight-bay Space Frame

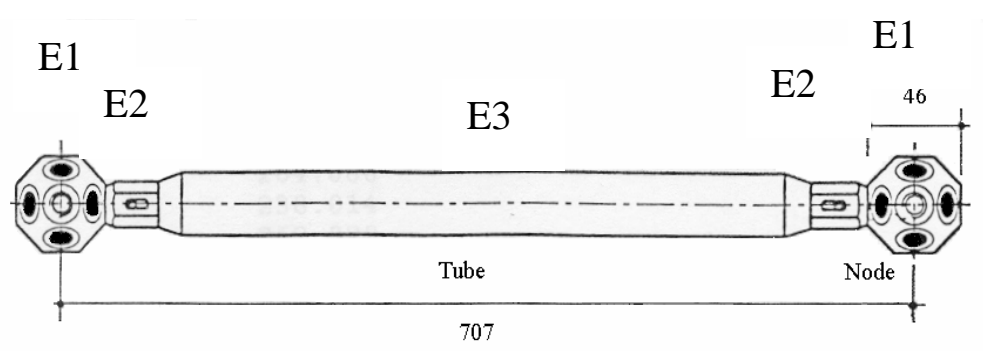

Fig. 4 Finite Element Model of the individual

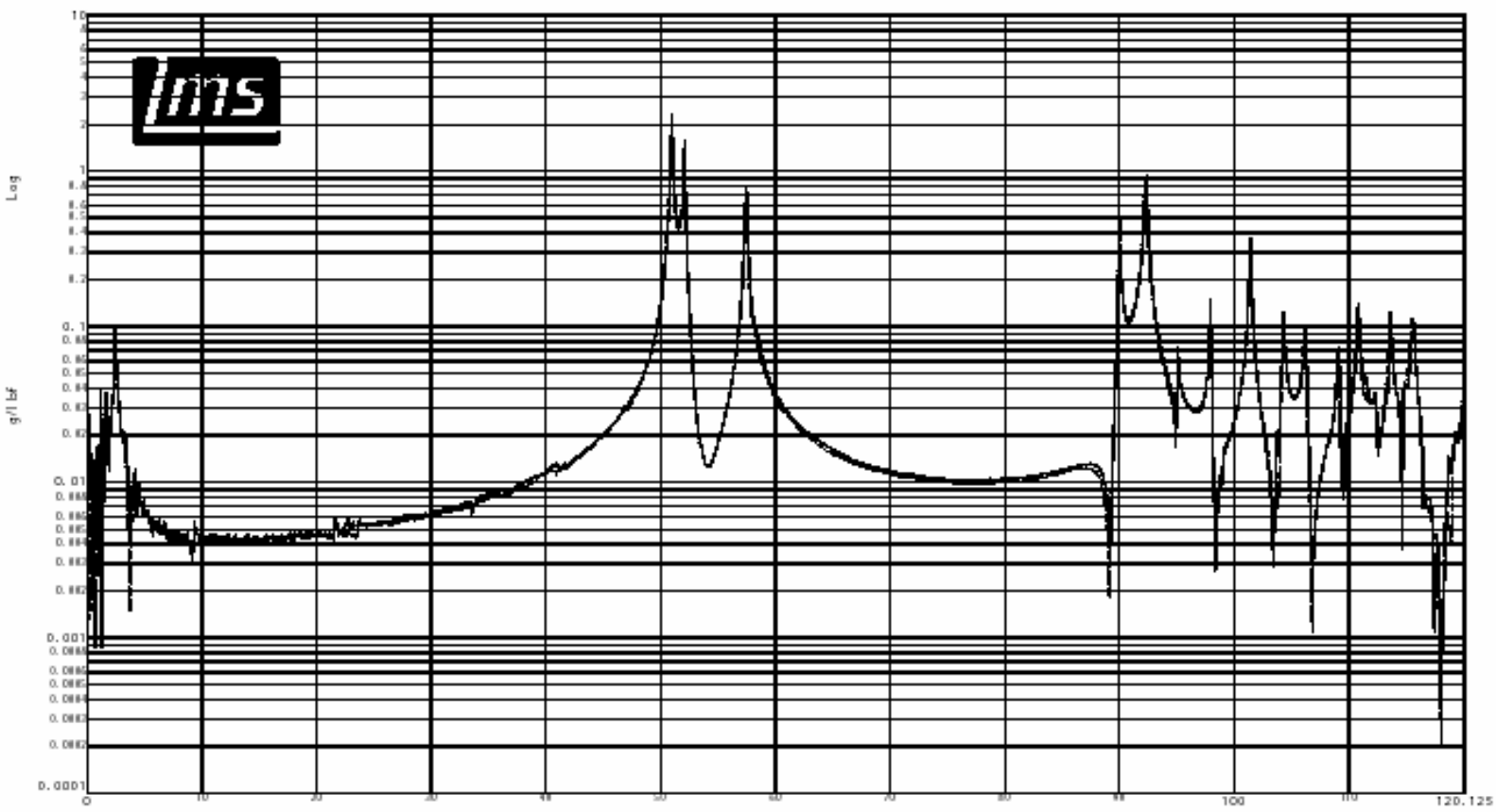

Fig. 5 FRF for the undamaged space frame at $(22-Y)$ due to excitation at (33-Z). 


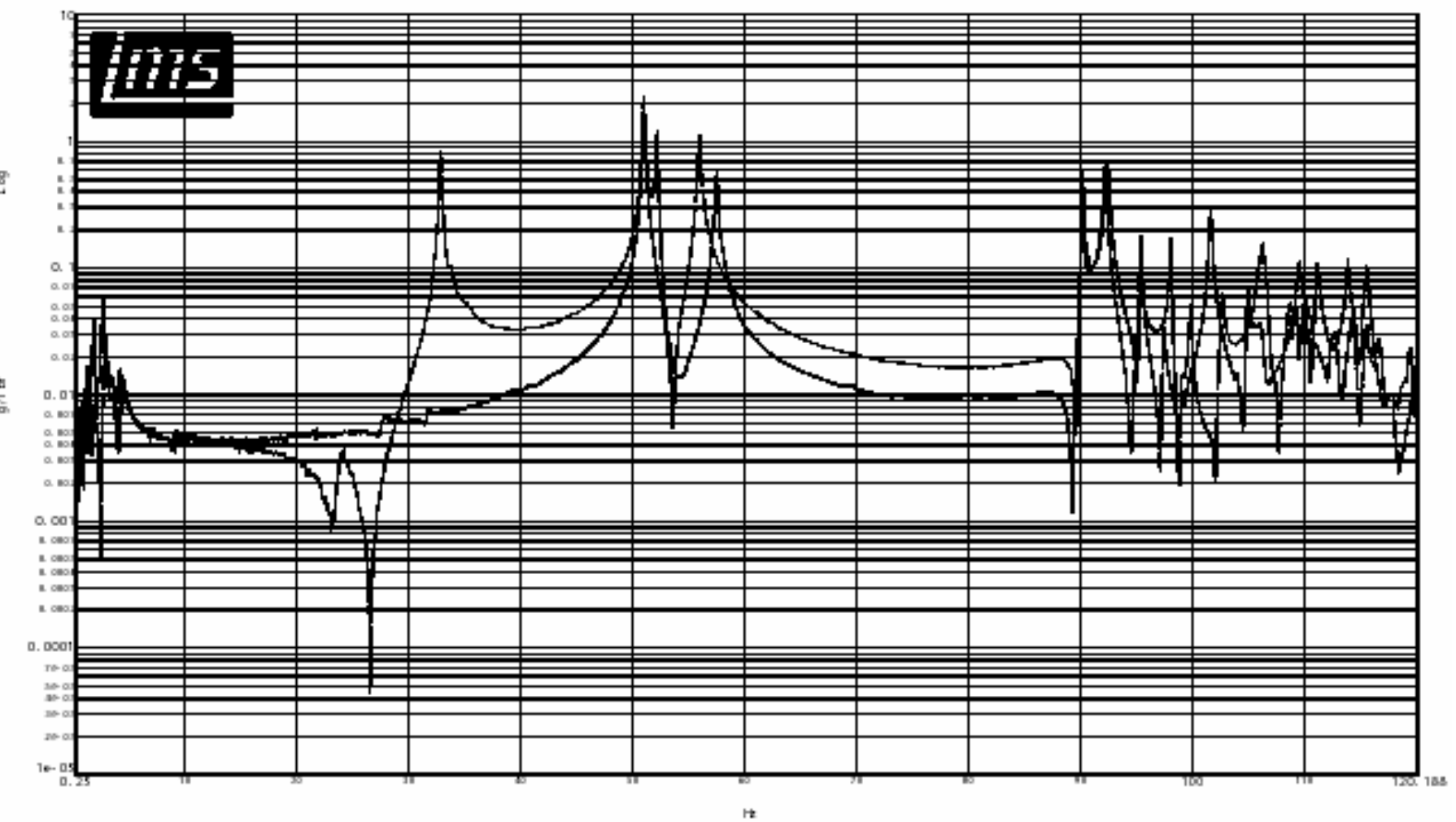

Fig. 6 Comparison of FRF before and after damage for damage case DE1: FRF measured at DOF (2-Y) due to excitation at DOF (33-Z).

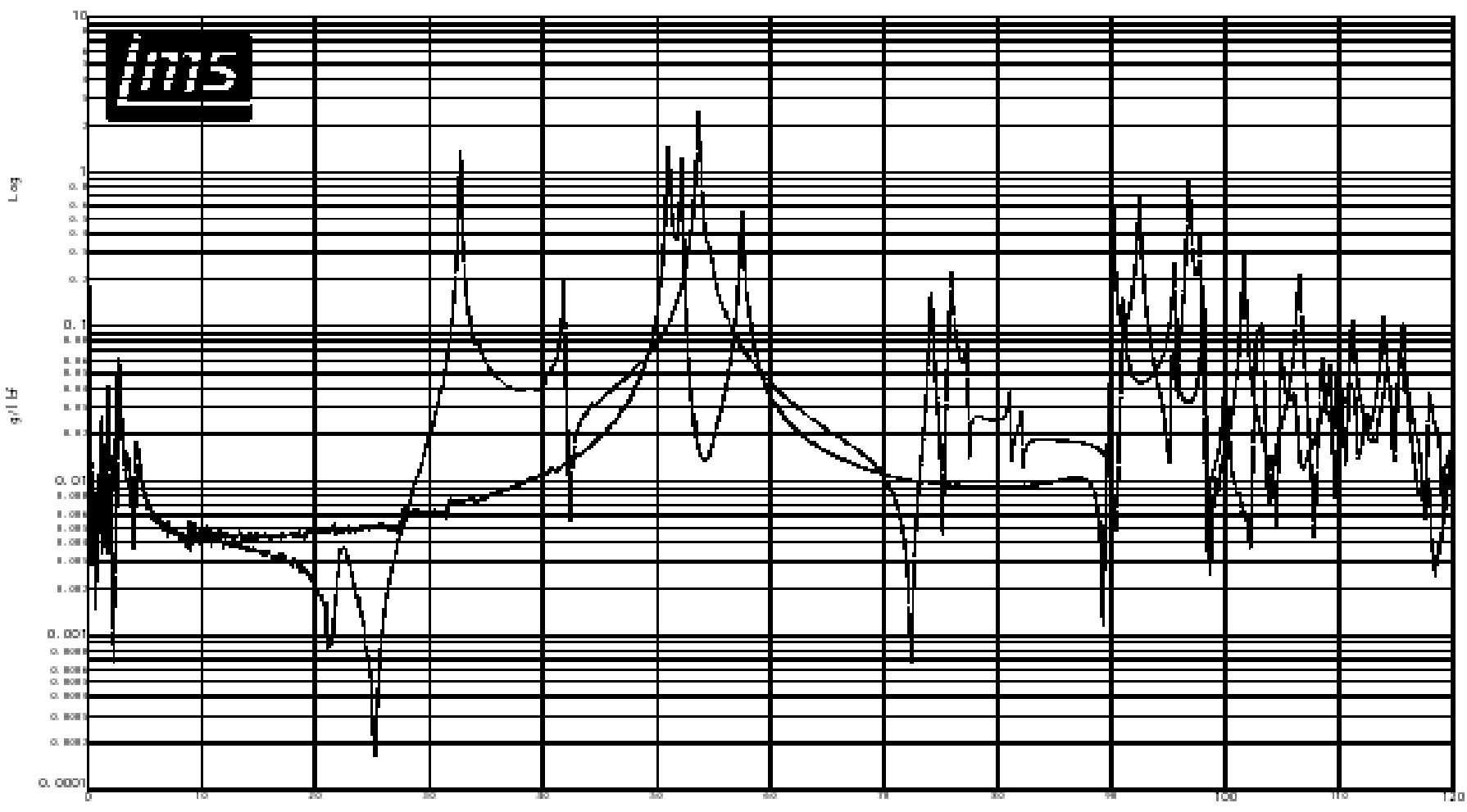

Fig. 7 Comparison of FRF before and after damage for damage case DE2: FRF measured at DOF (2-Y) due to excitation at DOF (33-Z). 


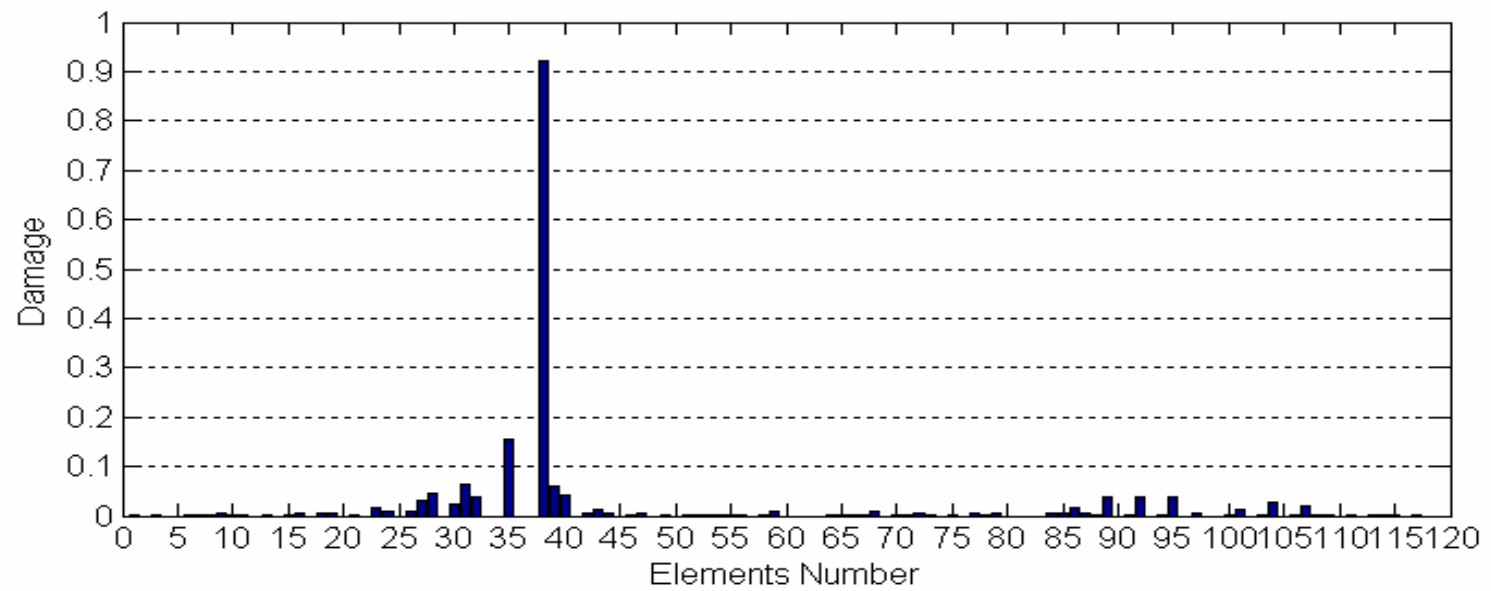

Fig. (8-a) Damage identification results for damage case DE1 using 109elements

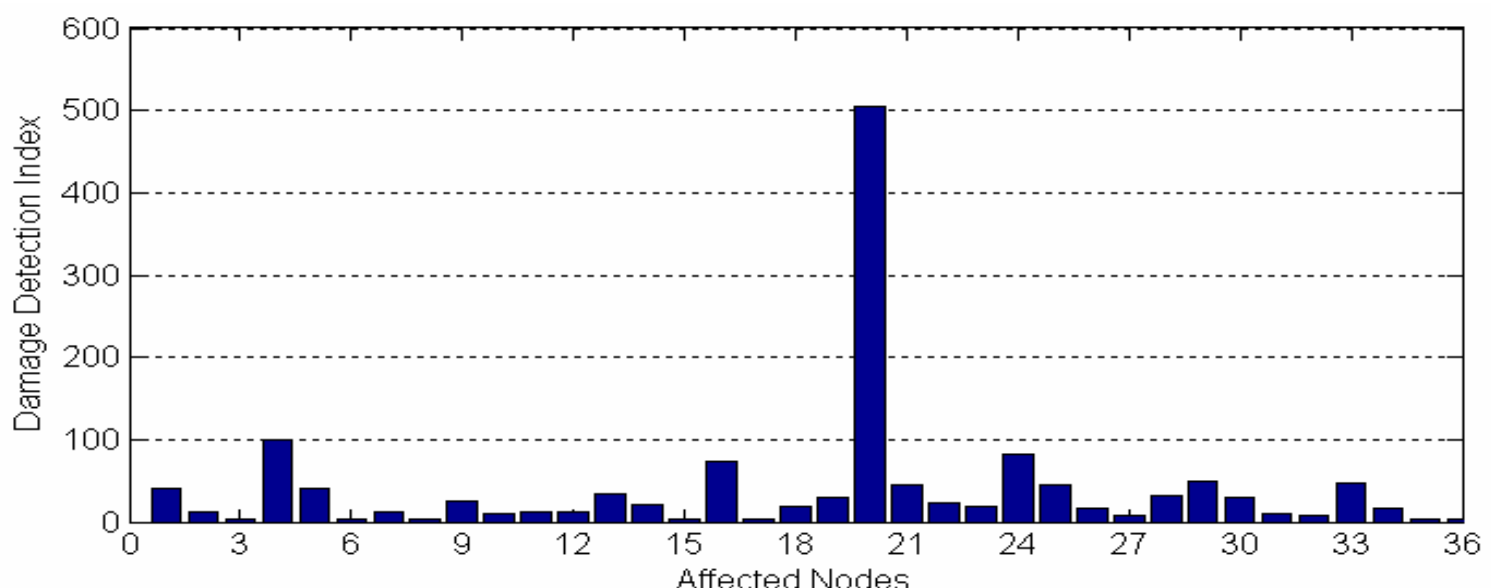

Fig. (8-b) DDI for damage case DE1 using FRFs measured at translational DOFs in the direction of $x$-axis due to excitation at DOF (2-y)

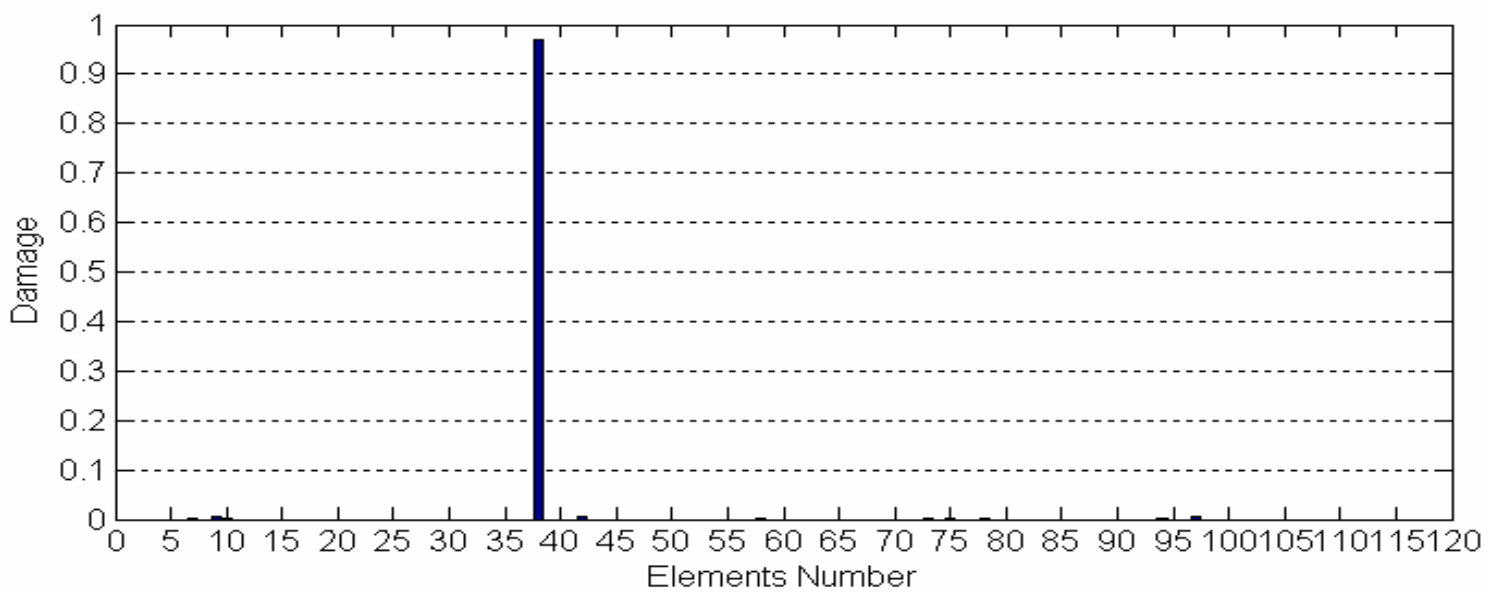

Fig. (8-c) Damage identification results for damage case DE1 based on region identification using DDI 


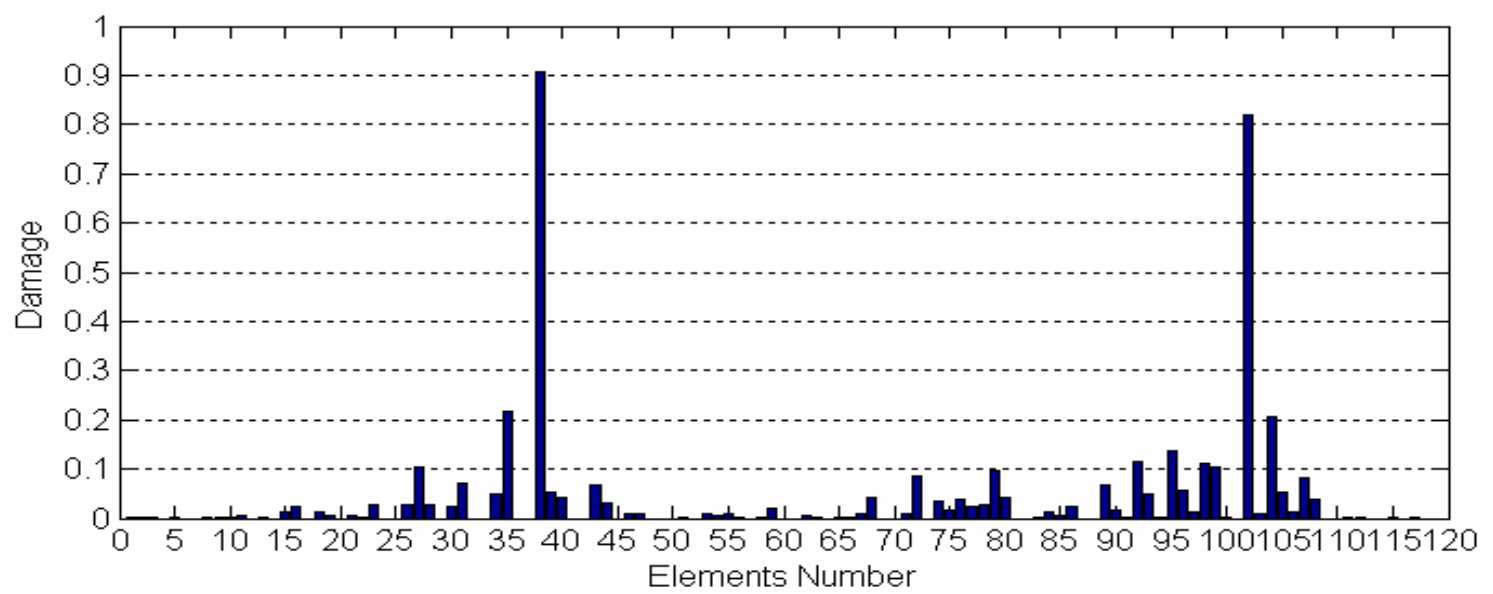

Fig. (9-a) Damage identification results for damage case DE2 using 109elements

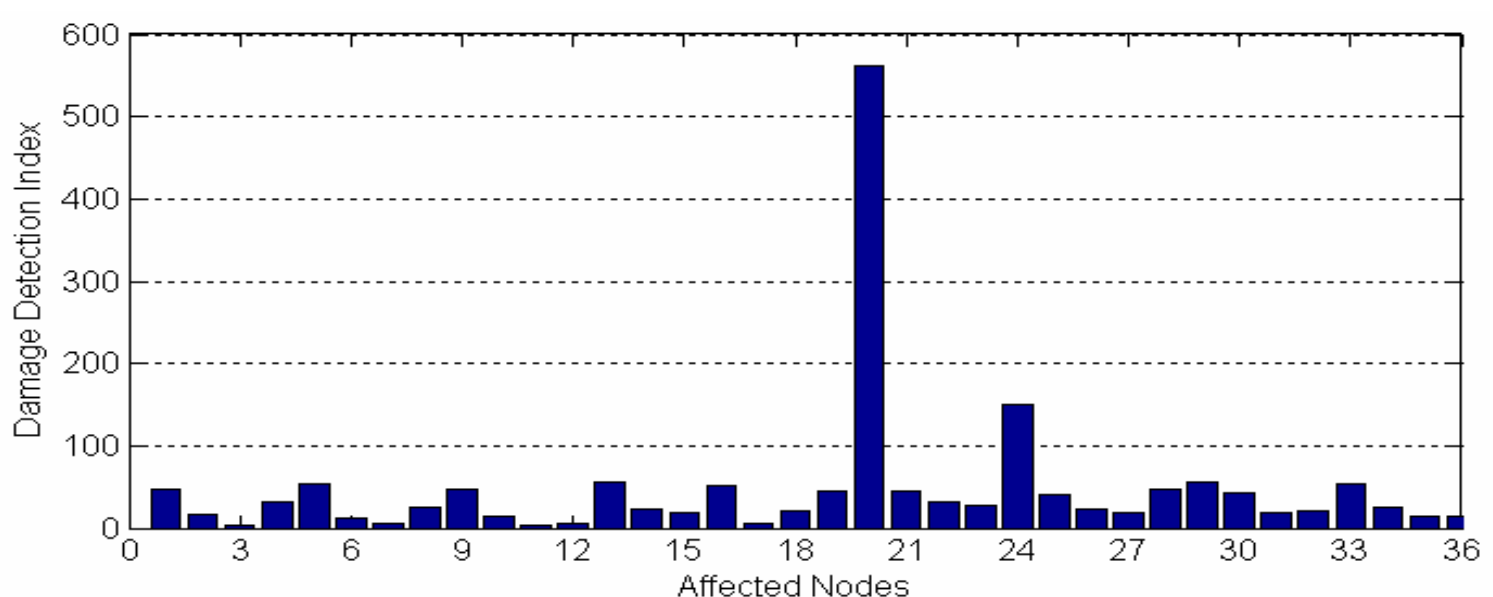

Fig. (9-b) DDI for damage case DE2 using FRFs measured at translational DOFs in the direction of $x$-axis due to excitation at DOF (2-y)

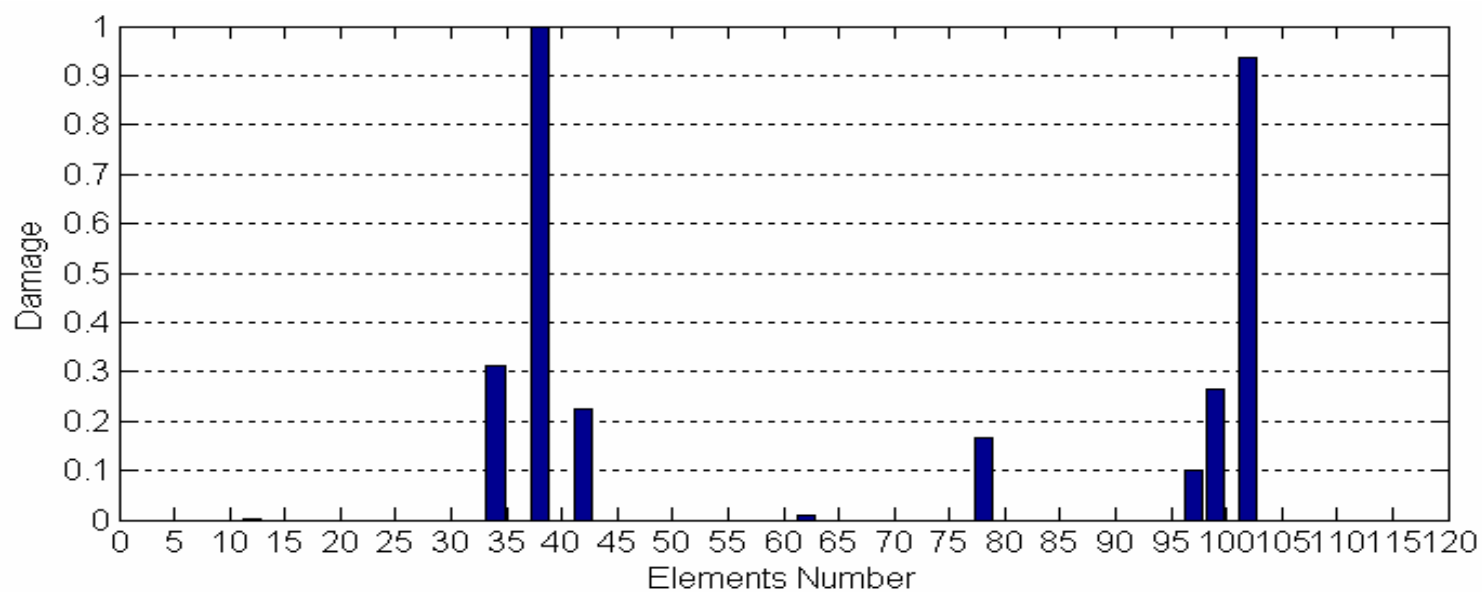

Fig. (9-c) Damage identification results for damage case DE2 based on region identification using DDI 


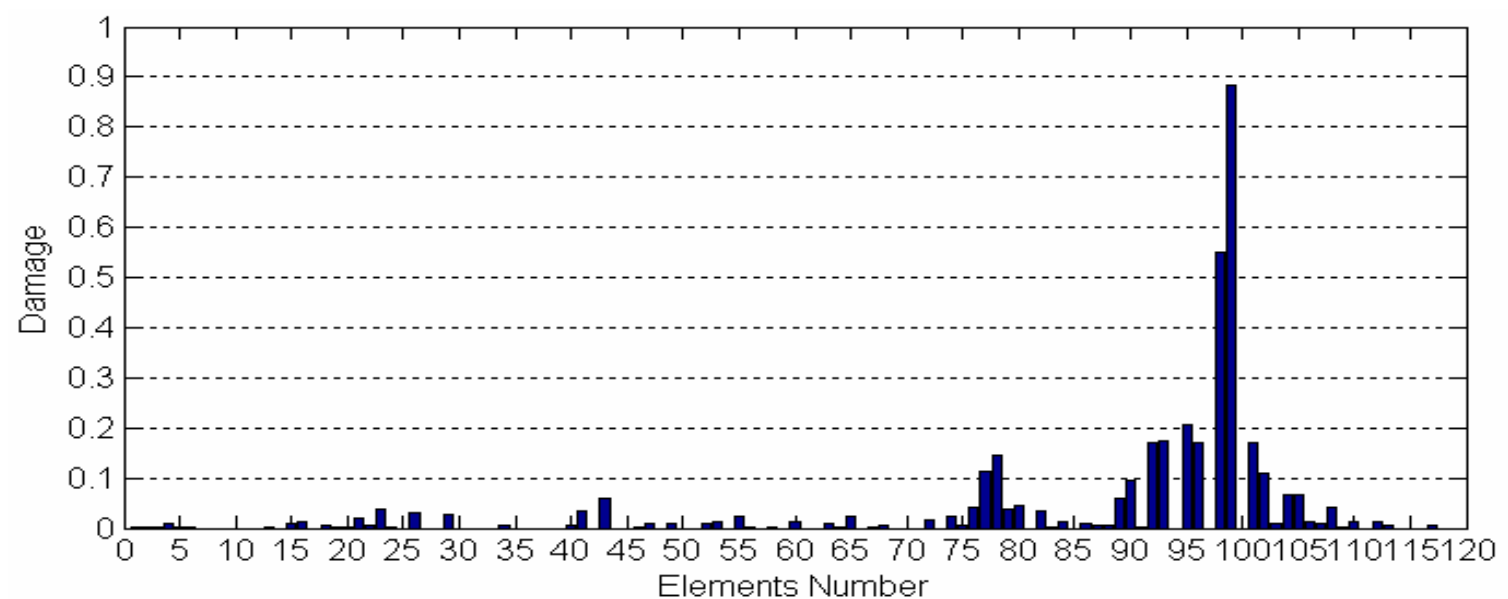

Fig. (10-a) Damage identification results for damage case DE3 using 109elements

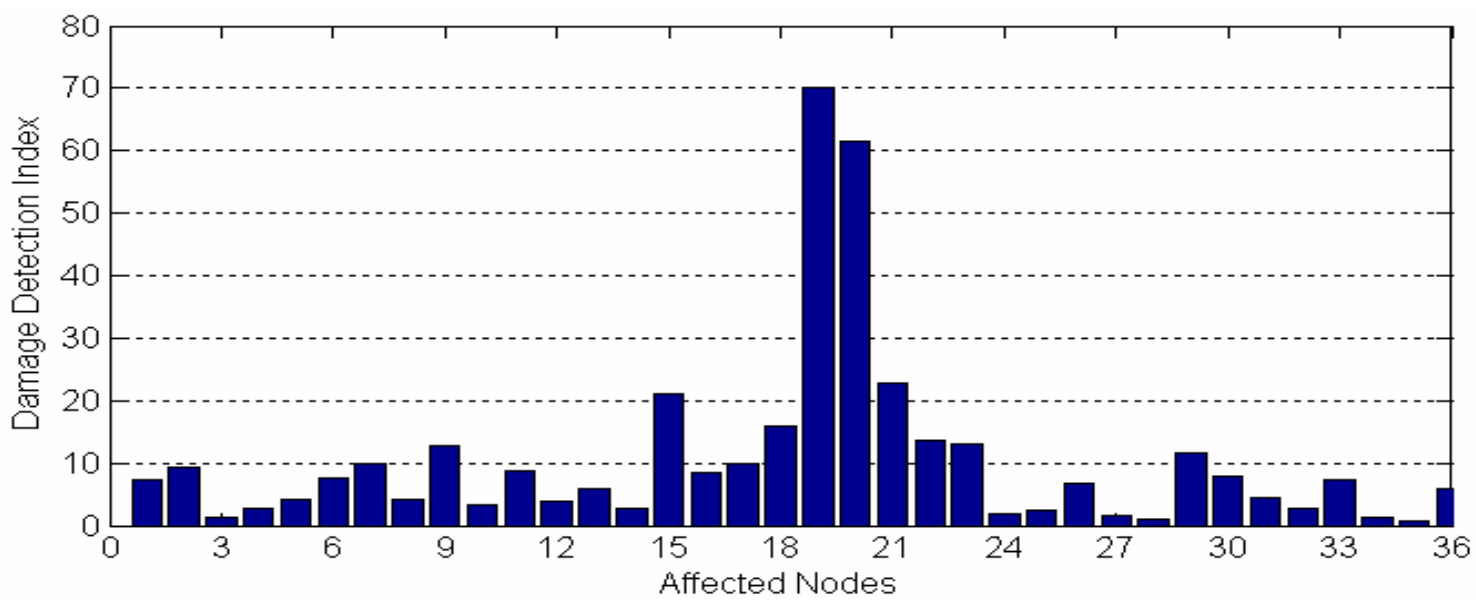

Fig. (10-b) DDI for damage case DE3 using FRFs measured at translational DOFs in the direction of $x$-axis due to excitation at DOF (2-y)

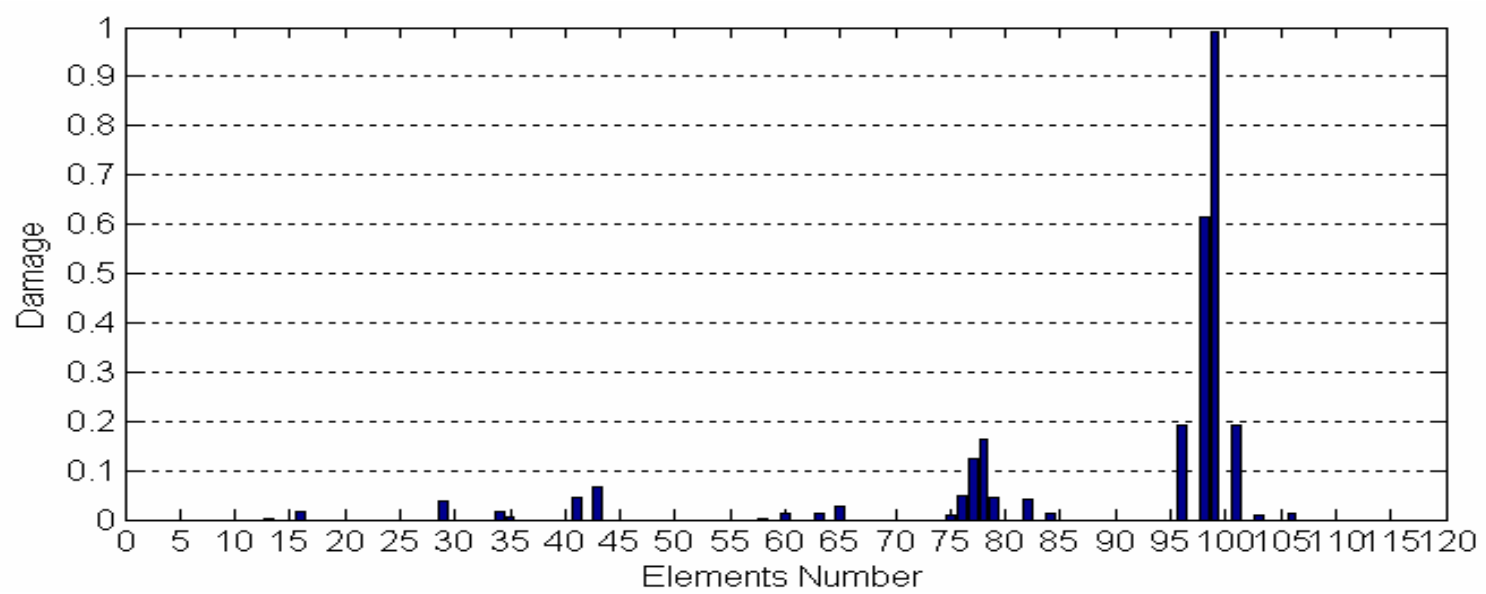

Fig. (10-c) Damage identification results for damage case DE3 based on region identification using DDI 


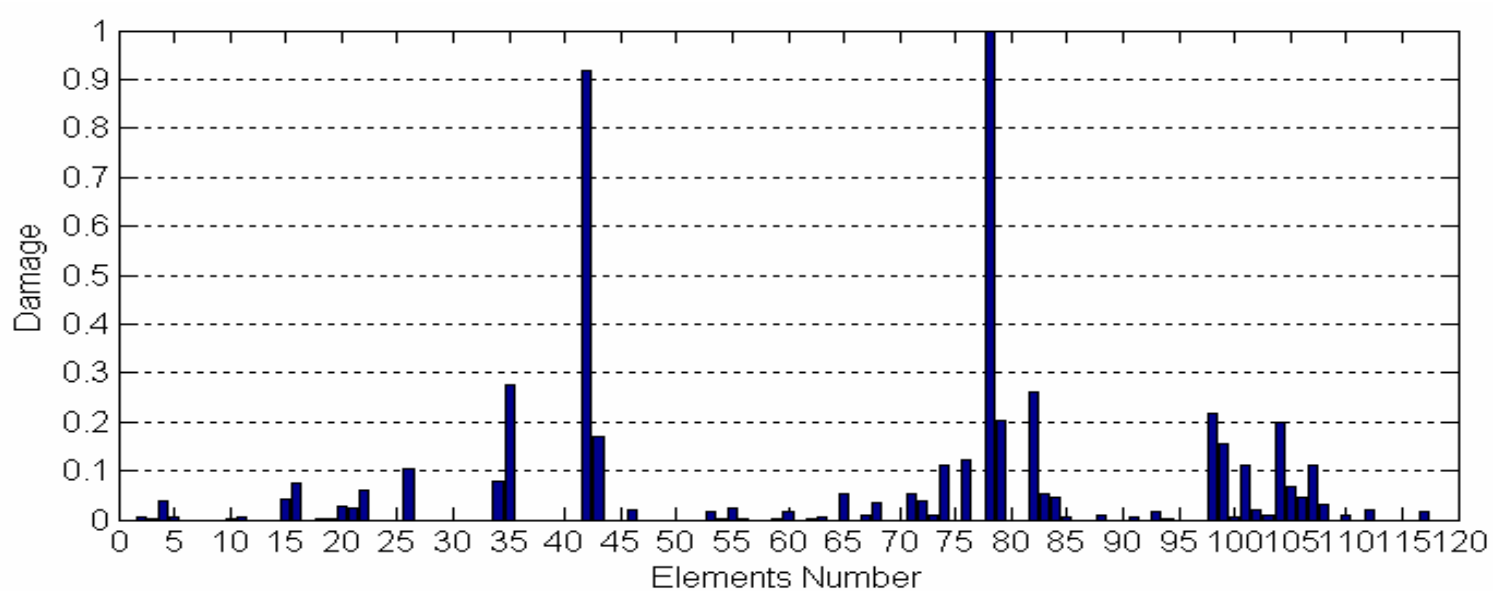

Fig. (11-a) Damage identification results for damage case DE4 using 109elements

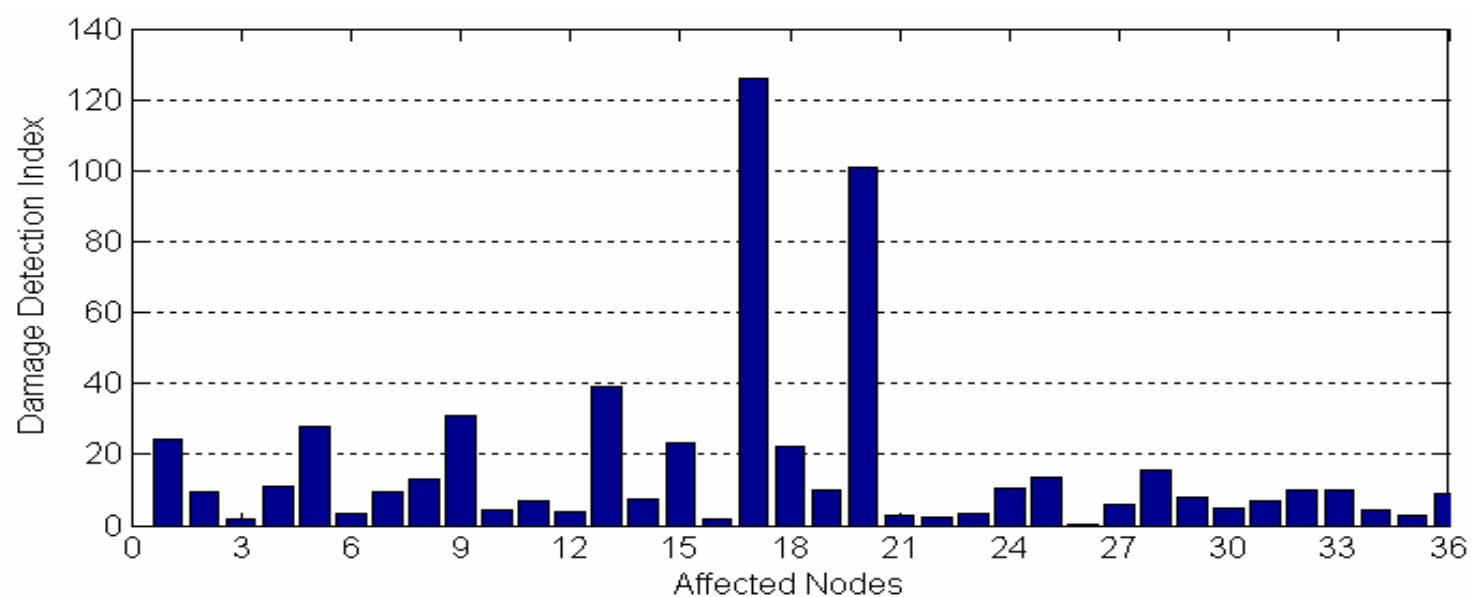

Fig. (11-b) DDI for damage case DE4 using FRFs measured at translational DOFs in the direction of $x$-axis due to excitation at DOF (2-y).

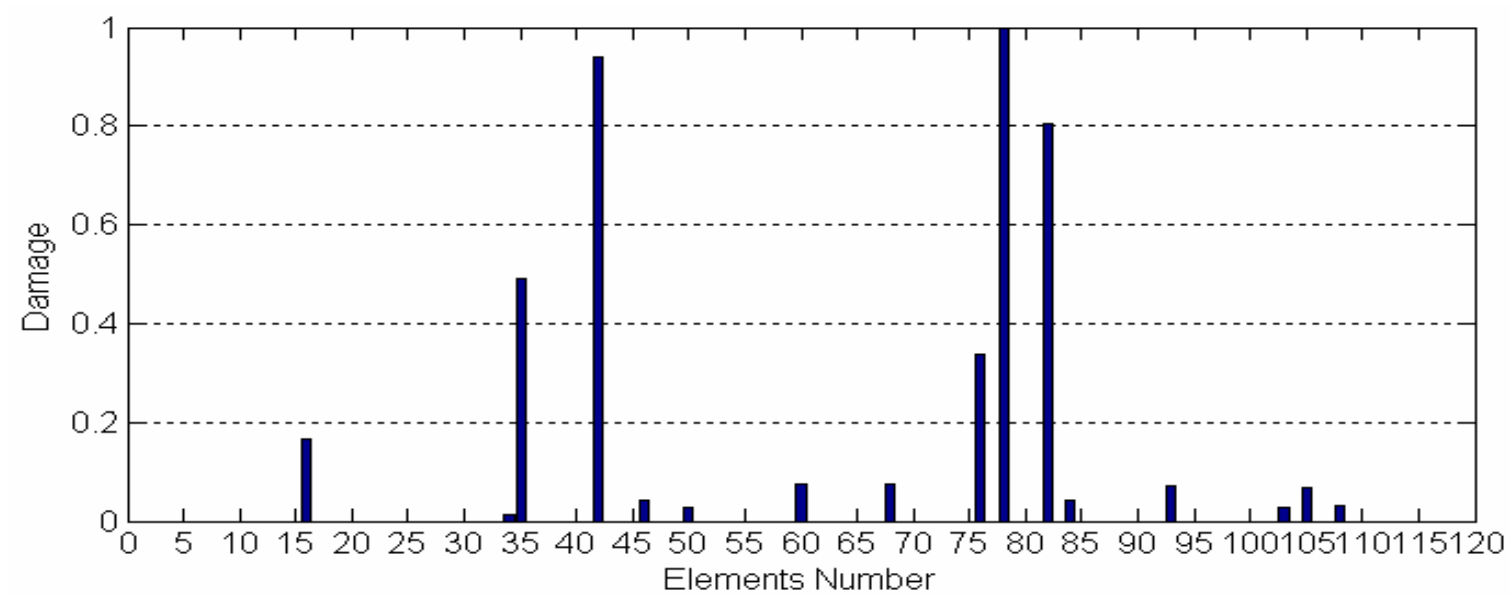

Fig. (11-c) Damage identification results for damage case DE4 based on region identification using DDI 


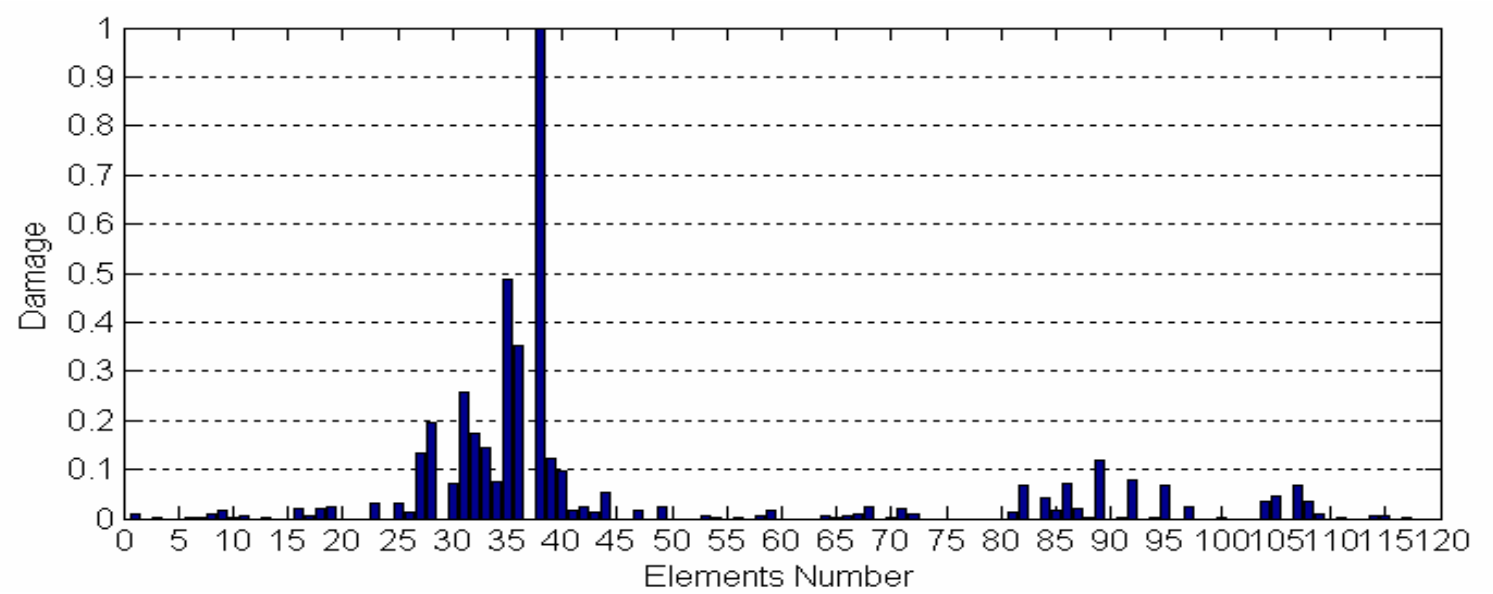

Fig. (12-a) Damage identification results for damage case DE5 using 109elements

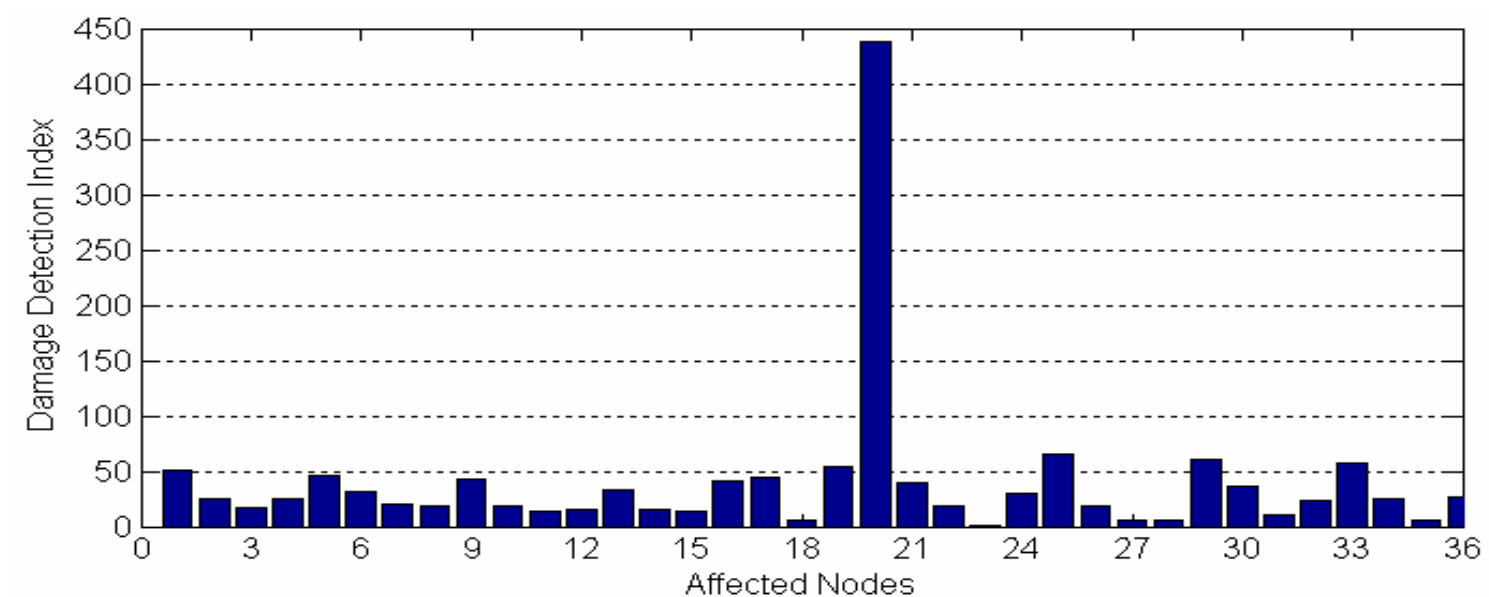

Fig. (12-b) DDI for damage case DE5 using FRFs measured at translational DOFs in the direction of $x$-axis due to excitation at DOF (2-y).

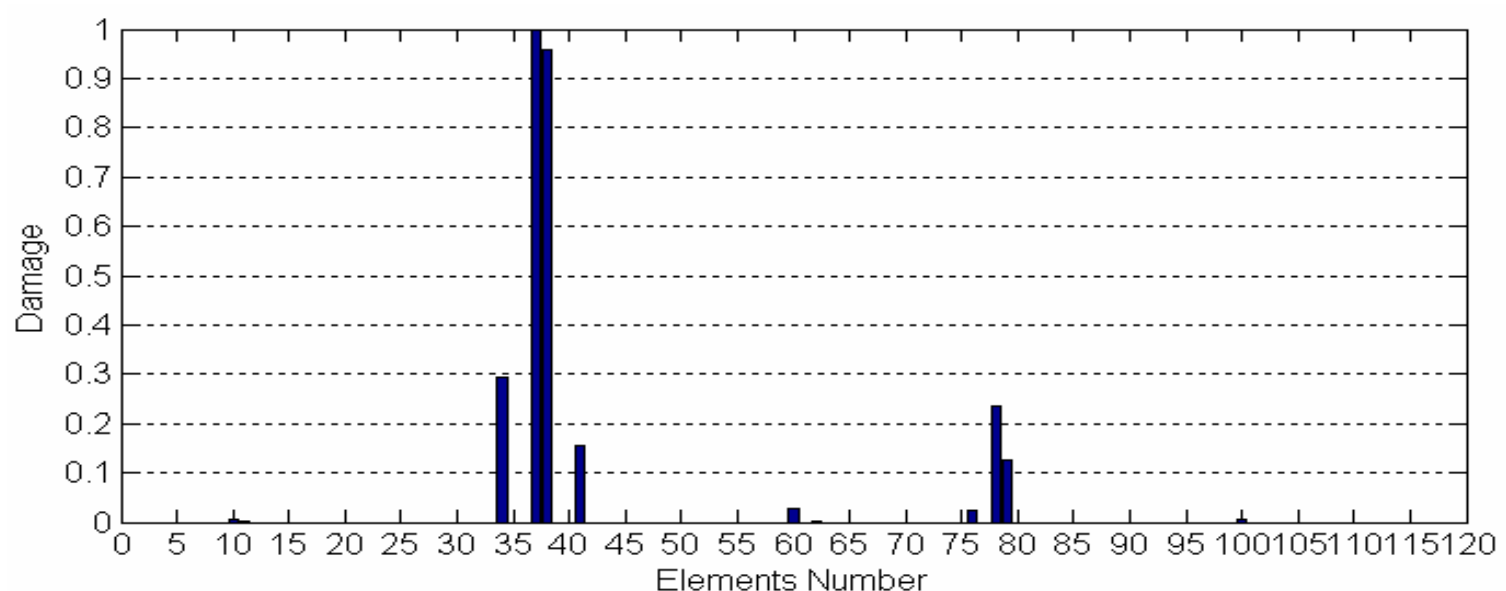

Fig. (12-c) Damage identification results for damage case DE5 based on region identification using DDI 